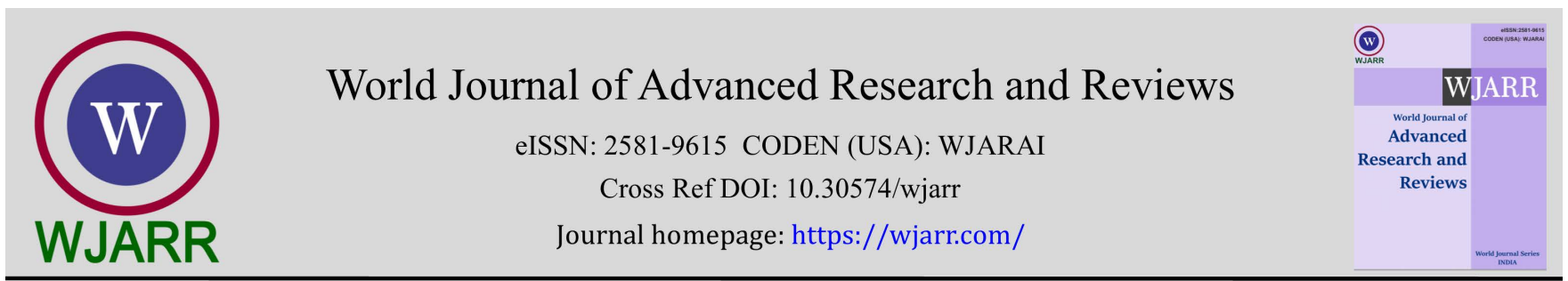

(RESEARCH ARTiClE)

\title{
Geodemographic perspectives in front of the western Balkans on the road to European integration
}

\author{
Kamen Petrov* \\ Department Regional Development, University of National and World Economy 1700 Sofia, Bulgaria
}

World Journal of Advanced Research and Reviews, 2021, 12(01), 155-161

Publication history: Received on 01 September 2021; revised on 07 October 2021; accepted on 09 October 2021

Article DOI: https://doi.org/10.30574/wjarr.2021.12.1.0505

\begin{abstract}
This article outlines the need for a general overview of the geodemographic state of several indicators in order to see the emerging socio-economic processes. The presentation shows that these countries have identical demographic and social problems, with the possible exception of the Albanians. Although the trend is emerging in all probability and they are facing similar trends with other countries. The derivation of the general geodemographic picture is a reason for the region to choose the implementation of European integration policies and programs that are consistent with the regional geodemographic approach of individual countries. In practice, bringing geodemographic problems to the forefront can be a successful milestone in the rapid and effective integration of these countries into the European Union.
\end{abstract}

Keywords: Population; Migration; Demography; Development; Integration; Movement; State

\section{Introduction}

The development of the number of inhabitants within the candidate countries and potential candidates followed a varied pattern during the period 2009-2020. The population of Turkey increased at a relatively rapid pace, growing by $14.7 \%$ overall during the period under consideration, while the number of inhabitants in North Macedonia and Montenegro grew at a modest pace, increasing by $1.4 \%$ and $0.8 \%$ respectively; this was similar to but slightly slower than the corresponding rate of change in the EU-27 where the population grew by $1.5 \%$ overall. Elsewhere there were relatively large declines in the populations of the candidate countries and potential candidates: down $2.5 \%$ in Albania, $5.1 \%$ in Serbia (note that there is a break in series), $8.9 \%$ in Bosnia and Herzegovina, and 17.7 \% in Kosovo. For the homogeneous development of the European Union, it is important to outline the demographic profile of the candidates for accession to it. The development of the number of inhabitants in the candidate countries and potential candidates follows a different model, but it is important in terms of modeling integration, as well as the behavior of the countries bordering them. These are Romania, Bulgaria, Croatia and Greece. These countries in the context of integration will have a significant role in building the single market and increasing the intensity of regional economic cooperation.

Spatially, the thesis of integration into the European Union is necessary in Southeast Europe. However, this is a complex process due to the instability of the region. The regional approach to the individual countries in this part of Europe is at the forefront. Thus, the Regional Approach connects the beginning of the real change in the policy of the European Union towards the Western Balkans, as well as towards Bulgaria and Romania. Unlike the Royamon Process, which has predominantly multilateral characteristics, the Regional Approach is more of a two-pronged initiative. It is intended only for the region of the Western Balkans and includes the republics of the former SFRY (excluding Slovenia) and Albania. It avoids some mistakes and omissions from previous years. The regional approach, for example, takes greater account of the specifics of the region as a whole and of the individual countries in it. It is designed in a way that allows

\footnotetext{
* Corresponding author: Kamen Petrov

Department Regional Development, University of National and World Economy1700 Sofia, Bulgaria

Copyright $(2021$ Author(s) retain the copyright of this article. This article is published under the terms of the Creative Commons Attribution Liscense 4.0.
} 
it to be transformed relatively quickly into a long-term and more effective common policy of the EU member states, in addition to the Royamo process (as it was at the beginning). The authors of the initiative define its main task as defining the future bilateral contractual relations between the mentioned countries and the European Union (EU). Through this initiative, the European Union is expected to actively support peace processes in the region and to stimulate the countries of the Western Balkans to accelerate regional cooperation and integration into the European Union. In practice, the integration of countries such as Albania, Serbia, Kosovo, Northern Macedonia and Bosnia and Herzegovina is quite a complex task, because not only a balance must be found between the integrating countries. A balance is also needed in their relations with neighbors such as Bulgaria, Greece and Turkey. To a large extent, it is also necessary to become clear with what population and what human capital the new countries will join the EU. The key problems facing the European future and the development of the West The Balkans not just as a periphery of Europe, but as a democratic and stable region, are defined by researchers as basically three. These are the status of Kosovo, reforms in Bosnia and Herzegovina and the Albanian national question, which are direct related to the broader challenge of overcoming ethnic intolerance, which continues to hang over the region today and hinders democracy development of the countries. At the moment, Serbia, Montenegro, North Macedonia and Albania are officially candidate countries for EU membership, as negotiations for accession are already under way for these countries. Bosnia and Herzegovina and Kosovo, respectively with the status of potential candidate countries in the European Union.

The European perspective for democratic development of the Western countries Balkans is the only useful move they can take to ensure prosperity, stability and peace in the region. The path to membership and integration it is undoubtedly difficult, difficult, slow and challenging for any country is at a different stage of its association process, but efforts in this direction are not they should subside both on their part and on the part of the European Union.

\section{Exposition}

The focus of the exhibition focuses on some demographic problems in these candidate countries for membership in the European Union, which are an important foundation for the development of trends and analysis of human capital as a driving force of socio-economic development. Thus, the derivation of the geodemographic potential and its analysis gives a real idea of what socio-economic change the region of the Western Balkans is facing. Our analysis begins with the Republic of Serbia and examines the other EU candidate countries and their demographic characteristics.

Table 1 Birth, death and natural increase table in Serbia

\begin{tabular}{|l|c|c|c|c|c|c|}
\hline \multicolumn{1}{|c|}{ Status } & $\mathbf{2 0 0 7}$ & $\mathbf{2 0 1 1}$ & $\mathbf{2 0 1 5}$ & $\mathbf{2 0 1 6}$ & $\mathbf{2 0 1 8}$ & $\mathbf{2 0 1 9}$ \\
\hline Born & 68.102 & 65.598 & 65.66 & 64.73 & 63.98 & 64.399 \\
\hline Died & 102.805 & 102.94 & 103.7 & 100.8 & 101.7 & 101.458 \\
\hline Natural growth & -34.703 & -37.337 & -38 & -36.1 & -37.7 & -37.059 \\
\hline \multicolumn{7}{|c}{ Source: Statistical Office of the Republic of Serbia }
\end{tabular}

The Republic of Serbia has an important fragment in the enlargement of the European Union. In practice, the Serbian state has been experiencing socio-economic difficulties for years. Relying on expert assessments, it has been gradually transformed and significant progress has been made in recent years. There have been significant demographic changes in Serbia over the last 30 years. They are a consequence of the war in the 1990s, which caused an influx of large numbers refugees from the former Yugoslav republics and internally displaced persons from Kosovo and Metohija, as well as massive emigration abroad, influencing the processes of urbanization and development of the Serbian space.

Thus, the Republic of Serbia has a population of 6963764 (together with Kosovo 8,737 371) people by 2020. Migration flows that lead to depopulation in some regions of the Republic of Serbia have also been caused by spatial characteristics, morphology of the terrain (mountainous areas) as well as peripheral position (border areas), where the lack of conditions leads to spontaneous resettlement. In the Republic of Serbia the Serbs comprise the majority of the population. According to the first results of the 1991 census, their share amounts to $65.6 \%$ of the total population in the Republic.

The data are also comparable with those of different countries and over time. The emerging negative demographic trends are complex. In the first place, the transformation of the Yugoslav space created conditions for insecurity and socio-economic deterioration of the situation on Serbian territory. Other factors are emigration, career development of young people, deteriorating health and others. The negative finding is the aging population, which could be a long-term problem for the functioning of Serbia's social system. 
In recent years, the beginnings of sustainable policies by the Serbian state have been noticed. On the other hand, it is too early to feel the results of the stabilization of the state and the effectiveness of governance. Serbia's accession to the European Union will be an important step towards improving security in the country, and hence more stable socioeconomic development.

Difficulties for Serbia may also be posed by ethnic differences in its territory. Difficulties for Serbia may also be posed by ethnic differences in its territory, especially relations with Kosovo. Because if we accept the data of the ethnographic condition, it can be seen that Albanians are in second place with $17.2 \%$, followed by Hungarians with $3.5 \%$, Muslims with $2.4 \%$, Montenegrins with $1.4 \%$ and Croats with $1.1 \%$. \%. It is important to note that since 2000, the Republic of Serbia has had a special status for the Administrative District of Kosovo. Poverty in Serbia is predominantly rural phenomenon as it affected rural areas more than twice as much as the cities in some periods.

Although in the Serbia the in poverty was much faster in rural than in urban areas, in 2019-2020, the overall growth of poverty was lounched in rural areas while the percentage of the poor in urban areas remained almost unchanged $(5 \%$ and $4.9 \%$, respectively). The growth of the poverty gap between cities and the countryside transmitted from year to year over the crisis, reaching a record rate of 2.6 in 2019. According to estimates, the working population in the Republic of Serbia by 2020 amounts to 4,5 million people. As can be seen from the table below, the population of Serbia is aging and young people aged 0 to 14 as a percentage are less than those over 65 when the population enters retirement age.

Table 2 Age structure of the population in Serbia in \%

\begin{tabular}{|l|l|l|l|}
\hline Age structure & $\mathbf{2 0 0 2}$ & $\mathbf{2 0 1 1}$ & $\mathbf{2 0 1 9}$ \\
\hline 0-14 years & $15.7 \%$ & $14.3 \%$ & $14.3 \%$ \\
\hline 15-64 years & $67.6 \%$ & $68.3 \%$ & $65.0 \%$ \\
\hline 65 and over & $16.7 \%$ & $17.4 \%$ & $20.7 \%$ \\
\hline \multicolumn{4}{|c|}{ Source: Statistical Office of the Republic of Serbia }
\end{tabular}

The age structure of a population affects a nation's key socioeconomic issues. Countries with young populations (high percentage under age 14) need to invest more in schools, while countries with older populations (high percentage ages 65 and over) need to invest more in the health sector. The age structure can also be used to help predict potential political issues. This deteriorating demographic structure is largely due to the continuing trend of declining birth rates and increasing mortality in Serbia.

Kosovo is located on the Balkan Peninsula with a total area of $10,908 \mathrm{~km}^{2}$. According to the first census conducted after the 2008 declaration of independence in 2011, the permanent population of Kosovo had reached 1,810,366 people. The main ethnic group is the Albanians, who make up the majority in Kosovo, with over 93\% of the total population, and significant minorities include Bosniaks (1.6\%), Serbs (1.5\%) and others. According to unofficial statistics, between 28,000 and 30,000 children are born annually, with mortality ranging from 9,500 to 12,000 per year. Thus, in Kosovo we have a positive natural population growth. The age structure of the population of Kosovo is relatively young and according to their statistical institute, the age group of 25-31 years is $25.1 \%$ of the population, and the group of $18-24$ years covers almost $21.4 \%$ of the population. However, the education of the population is dominated by secondary education or $44.9 \%$ of the population, those with primary education make up $34 \%$, but those with higher education and universities are one $8.6 \%$.

Kosovo should benefit far more than it does from its young population but the lack of jobs and opportunities remain an obstacle to growth and a spur to emigration. In practice, we are witnessing that Kosovo's population growth may be rapid, but it does not correspond to the relatively slow economic development. This creates an imbalance and the phenomenon of internal and external migration. Based on this pattern regions with high birth rates are almost always or in most cases emigrant areas, as is the case in Kosovo.According to some authors, the current state of the ethnic map, trends and The prospects for the region call for one, though not the best, but one of the most acceptable and reasonable solutions - the unification of the Albanians in one country. this is presents as the only way to save new territories from lasting and irreversible Albanianization and from new clashes and ethnic conflicts with unpredictable consequences. 
Table 3 Ethnic composition and population of Kosovo by 2020

\begin{tabular}{|l|c|l|}
\hline Language & Native language & \% \\
\hline Albanian & $1,644,865$ & 94.5 \\
\hline Bosnian & 28,989 & 1.7 \\
\hline Serbian & 27,983 & 1.6 \\
\hline Turkish & 19,568 & 1.1 \\
\hline Romani & 5,860 & 0.3 \\
\hline Other/Not specified & 12,560 & 0.7 \\
\hline Romani & 5,860 & 0.3 \\
\hline
\end{tabular}

Table 4 Comparison of the Population in 2016 and 2020 in Albania

\begin{tabular}{|c|c|c|c|c|c|c|}
\hline \multirow[b]{2}{*}{ Age group } & \multicolumn{3}{|c|}{2016} & \multicolumn{3}{|c|}{2020} \\
\hline & Men & Women & Total & Men & Women & Total \\
\hline $0-4$ & 87,739 & 80,681 & 168,420 & 76,045 & 71,862 & 147,907 \\
\hline $5-9$ & 87,364 & 79,179 & 166,543 & 83,364 & 80,821 & 164,185 \\
\hline $10-14$ & 102,819 & 93,825 & 196,644 & 85,586 & 81,172 & 166,758 \\
\hline $15-19$ & 119,828 & 114,883 & 234,711 & 100,459 & 96,874 & 197,333 \\
\hline $20-24$ & 133,298 & 123,601 & 256,899 & 112,810 & 113,615 & 226,425 \\
\hline $25-29$ & 122,534 & 102,171 & 224,705 & 120,166 & 117,441 & 237,607 \\
\hline $30-34$ & 97,743 & 87,193 & 184,936 & 105,848 & 95,093 & 200,941 \\
\hline $35-39$ & 80,527 & 81,023 & 161,550 & 89,125 & 85,047 & 174,172 \\
\hline $40-44$ & 82,084 & 87,716 & 169,800 & 79,021 & 81,498 & 160,519 \\
\hline $45-49$ & 91,151 & 97,707 & 188,858 & 83,241 & 89,259 & 172,500 \\
\hline $50-54$ & 100,409 & 101,945 & 202,354 & 91,819 & 97,345 & 189,164 \\
\hline $55-59$ & 97,238 & 97,842 & 195,080 & 99,754 & 103,365 & 203,119 \\
\hline $60-64$ & 77,900 & 79,285 & 157,185 & 90,642 & 94,647 & 185,289 \\
\hline $65-69$ & 60,750 & 61,923 & 122,673 & 69,329 & 72,995 & 142,324 \\
\hline $70-74$ & 49,084 & 50,210 & 99,294 & 53,056 & 56,701 & 109,757 \\
\hline $75-79$ & 38,436 & 41,013 & 79,449 & 41,534 & 44,457 & 85,991 \\
\hline $80-84$ & 20,627 & 23,339 & 43,966 & 26,298 & 29,391 & 55,689 \\
\hline $85+$ & 8,920 & 13,605 & 22,525 & 12,516 & 13,759 & 26,275 \\
\hline Total & $1,458,451$ & $1,417,141$ & $2,875,592$ & $1,420,613$ & $1,425,342$ & $2,845,955$ \\
\hline
\end{tabular}

It is important to stress that there are common actions between Albania and the Kosovo Administrative District, but on the other hand there are also differences, and perhaps their own paths for the present and the future. 
During the Balkan War, on November 28, 1912, Albania declared its independence from the Ottoman Empire with the Vlora Declaration. In many respects, Albania does not differ significantly from the other Balkan countries. "The Land of the Eagles" shares to largely the fate of the peoples of the region, but at the same time there are also some characteristics typical only for her. Until the early 90 -in those years of the last century it was the most closed, the most self-isolated is a country not only in the Balkans but also in Europe and therefore not at all coincidentally, her most famous "business card" for the outsider The world has numerous bunkers (many "count" more than seven hundred thousand, and others even reach one million). The path of the Republic of Albania in its development has its strengths and weaknesses, but in general the country is gradually developing and with the accession and NATO becomes part of the European Atlantic family. In economic aspect Albania will continue its upward economic development, which will is based on investments from the diaspora, considerable, for the scale of the Albanian economy, natural resources, and thanks to progress in building the rule of law. Together with positive trends in the security environment, the analysis of the internal state of Albania shows that a number of factors continue to operate prerequisites for destabilization of the country and may have negative consequences in regional scale.

Albania is a fairly linguistically homogeneous country with ethnic Albanians forming the majority in the country. Albania has 2,845,955 inhabitants according to the INSTAT calculations current as of 1 January 2020. The population density is 98.5 inhabitants per square kilometer, and the total life expectancy in Albania at birth was 78 years in the period 20112020. In recent years, a census has been conducted in urban areas (53.7\%) and rural areas (46.3\%). It has been found that urban lifestyle is already prevalent in Albania in the 21st century. Within the national territory, the Albanian language is being established as an official language, but minority languages are officially used in some local state units. Albanian is declared the mother tongue of $98.76 \%$ of the population. On 1 January 2020 the youth dependency ratio (ratio of the number of persons under working age 0-14 with the number of persons of working age 15 to 64 ) has decreased compared to first January 2019 , from $25.1 \%$ to $24.6 \%$. The old dependency ratio (ratio of the number of persons above the working age $65+$ with the number of persons of working age 15 to 64 ) has increased from $20.5 \%$ to $21.6 \%$ in the same period.

This chapter provides an overview of recent developments in the Albanian population, taking into account some of the key demographic indicators, including information on changes in number of population over the period 2016-2020, such as: population density, fertility, life expectancy and age dependency ratios. Presented indicators highlight a slight decrease of population during the given period, which is approaching the aging process, as result of increasing life expectancy, as well as fertility that still remains below replacement level. Population and population change The latest demographic developments show that Albanian population is decreasing, while population structure shows that population is moving towards aging process. This comes due to the increase in life expectancy, as well as fertility on the other hand that still remains below replacement level. In 2019 the old age dependency ratio in Albania is $20.1 \%$ against $17.9 \%$ in 2016. On the other hand, young age dependency ratio in 2019 is $25.4 \%$ against $28.2 \%$ in 2016 , showing a downward trend of this ratio in country.

Table 5 Average age of the population in Northern Macedonia

\begin{tabular}{|l|c|c|c|c|c|c|}
\hline & \multicolumn{3}{|c|}{ Age limit } & \multicolumn{3}{c|}{ Middle-aged } \\
\hline Year & $\mathbf{2 0 1 4 - 2 0 1 6}$ & $\mathbf{2 0 1 5 - 2 0 1 7}$ & $\mathbf{2 0 1 6 - 2 0 1 8}$ & $\mathbf{2 0 1 6}$ & $\mathbf{2 0 1 7}$ & $\mathbf{2 0 1 8}$ \\
\hline Total & 75.40 & 75.57 & 75.95 & 38.7 & 39.0 & 39.2 \\
\hline Men & 73.45 & 73.66 & 74.00 & 37.9 & 38.1 & 38.4 \\
\hline Women & 77.41 & 77.52 & 77.94 & 39.6 & 39.8 & 40.1 \\
\hline
\end{tabular}

According to the State Statistical Office data in the Republic of North Macedonia there were 19986 births, of which 19 845 live births and 141 stillbirths. In 2019, compared to the previous year, the number of live births decreased by $7.0 \%$. The structure of live births by sex was dominated by boys with $51.8 \%$, which means there were 107.4 boys per 100 girls. in general, the demographic structure of the population in North Macedonia shows a positive natural example. It can be assumed that it is due to the ethnic groups in it, but in general there are positive results. The population growth is due to the natural increase and immigration in the region. About $35 \%$ of the total internal migration movements in the country took place only towards the Skopje region and within the region in the period 2005-2015. This intensive immigration has certain specificities. Most evident is the direction of movement of the migrants from other regions to certain parts of the Skopje region, more precisely to a place where someone from their previous area of residence had already moved, or an area that is spatially closer to them. Most attractive immigration location are the city 
municipalities. $60 \%$ of all immigrants to the Skopje region have moved only in four municipalities of the city of Skopje. The analysis of migrants by place of origin shows that the majority of immigrants are from the Northeast region, while the smallest share of only $8.2 \%$ is from the Southeast region. The change in the percentage is directly related to the intensive migration movements abroad. International migration covers the migration of citizens of the Republic of North Macedonia from the country to another country and vice versa, as well as the migration of foreigners.

Bosnia and Herzegovina is situated in the west part of the Balkan Peninsula. Border countries Serbia and Montenegro on the east, Republic of Croatia on the north, west and south. Bosnia and Herzegovina is divided into cantons and municipalities. The federation has 79 municipalities. Republika Srpska is administratively divided into 62 municipalities.

Table 6 Demographic characteristics of the population in Bosna and Herzegovina

\begin{tabular}{|l|c|c|c|c|c|}
\hline & Average population & Live births & Deaths & Natural change & Crude birth rate (per 1000) \\
\hline 2016 & $3,447,001$ & 29,985 & 36,065 & $-6,080$ & 2016 \\
\hline 2017 & $3,437,453$ & 30,061 & 37,453 & $-7,392$ & 8.7 \\
\hline 2018 & $3,427,369$ & 29,328 & 37,237 & $-7,909$ & 8.6 \\
\hline 2019 & $3,415,752$ & 28,192 & 38,237 & $-10,045$ & 8.3 \\
\hline
\end{tabular}

The town of Brchko is a separate administrative unit. Bosnia and Herzegovina is known for its diversity of peoples and ethnic minorities who live in it. The structure of population Bosnians, Serbs, Croats, and other participants of others nations. Official languages are Bosnian, Serbian and Croatian (Bosnian, and Croatian are written on Alphabet, and Serbian are written on Cyrillic). Minorities living in Bosnia and Herzegovina use their native languages in their mutual communication. Dominant monotheistic religions coexist in Bosnia and Herzegovina: Islam, Orthodoxy, Catholicism and Judaism and other religions. According to the Constitution of Bosnia and Herzegovina, all its citizens have equal rights and freedoms in exercising their religious and other beliefs. Over the years, governance reforms have been slow in Bosnia and Herzegovina. The aim of the country is to be able to gradually adapt to the common European policies for sustainable development and future EU membership. Bosnia and Herzegovina's application for EU membership was submitted on 15 February 2016. The state of Bosnia and Herzegovina in terms of population is not good. It has decreased in recent years with a negative natural increase of more than 8 per thousand. There is also a tendency for population aging and problems in the regional economic development of the individual cantons and common in the country. According to the official authorities in Bosnia and Herzegovina, nearly 2 million people of Bosnian origin have emigrated from Bosnia and Herzegovina, which is $56.6 \%$ of the rest of the country's population. The largest number of emigrants was in Croatia - 394,146 people, the second is Serbia, where 333,687 people of Bosnian origin live, and the third is Germany with 200,510 people. Followed by Austria, USA, Slovenia, Switzerland, Sweden and Canada. There is a serious tendency to emigrate from Bosnia and Herzegovina not only highly educated people, but also other categories, and highly educated people often start work that does not require such qualification. This shows that Bosnia and Herzegovina needs new reforms and policies that give a new socio-economic horizon for the development of the national economy.

\section{Conclusion}

The Regional Geodemographic approach is associated with the beginning of a real change in the European Union's policy towards the Western Balkans. Unlike the Royamon Process, which has predominantly multilateral characteristics, the regional geodemographic approach also focuses on a series of social and demographic policies. This approach is intended for the Western Balkans region. It avoids some mistakes and omissions from previous years. The regional geodemographic approach, for example, takes greater account of the demographic specifics of the region as a whole and of the individual countries in it. It is designed to encourage the countries of the Western Balkans to speed up regional co-operation. Of course, the candidate countries for membership in the European Union face many ethno-confessional problems. Their solution will not be easy either, but it is important to define the main geodemographic problems for the countries of the Western Balkans. On the other hand, it will undoubtedly be a great success for a united Europe if the countries of the Western Balkans can be integrated into the union. Experience shows that the regulation of geodemographic processes generates security and stability in each region. This means that when the demographic 
problems begin to be solved, the speed of European integration and the socio-economic development of the region will increase.

\section{Compliance with ethical standards}

\section{Acknowledgments}

I am so happy and thankful that I have a change to be published in your journal! Best Wishes to all of Editorial Team!

\section{Statement of informed consent}

The studies don't involve information about any individual e.g. case studies, survey, interview etc.

\section{References}

[1] Demography. Agency for Statistics of Bosnia and Herzegovina. 2018.

[2] Natural population change. State statistical office, N.Macedonia. 2019.

[3] Sustainable development goals. INSTAT Republic of Albania, Tirana. 2020.

[4] Statistical Yearbook of the Republic of Serbia. Statistical Office of the Republic of Serbia. 2020.

[5] STATISTICAL POCKETBOOK Belgrade. Statistical Office of the Republic of Serbia. 2020.

[6] Statistical Yearbook of the Repubic of Kosovo. Kosovo Agency of Statistics. 2019. 